\title{
Edukasi Perilaku Orang Tua dalam Pemberian MP-ASI pada Balita di Dusun Kodokan
}

\author{
Nur Ani ${ }^{1}$, Farid Setyo Nugroho ${ }^{2}$, Wartini ${ }^{3}$ \\ FKM Universitas Bangun Nusantara Sukoharjo ${ }^{1,2,3}$ \\ *e-mail: aninurk3@gmail.com
}

\begin{abstract}
Abstrak
Periode tumbuh kembang emas pada bayi dan anak dapat diwujudkan apabila memperoleh asupan gizi yang sesuai. Guna mencapai tumbuh kembang yang optimal, di dalam Global Strategy for Infant and Young Child Feeding, WHO/UNICEF merekomendasikan empat hal penting yang harus dilakukan yaitu; pertama memberikan air susu ibu kepada bayi segera dalam waktu 30 menit setelah bayi lahir, kedua memberikan hanya air susu ibu (ASI) saja atau pemberian ASI secara eksklusif sejak lahir sampai bayi berusia 6 bulan, ketiga memberikan makanan pendamping air susu ibu (MP-ASI) sejak bayi berusia 6 bulan sampai 24 bulan, dan keempat meneruskan pemberian ASI sampai anak berusia 24 bulan atau lebih (WHO, 2000). Berdasarkan observasi data di Posyandu Dusun Kodokan bahwa sebagian besar ibu balita atau anggota keluarga dekat telah memberikan MP-ASI dini sebesar (70\%) dari jumlah balita yang ada yaitu 55 balita dan dari 55 orang ibu balita. Balita yang ada di Posyandu Dusun Kodokan ini terdiri dari usia $0-6$ bulan (7,3\%), usia $7-12$ bulan (10,9\%), usia 1-3 tahun (47,3\%), usia 4-5 tahun (34,5\%). Sebagian besar pendidikan terakhir ibu balita di Dusun Kodokan rata-rata Sekolah Menengah Atas (SMA/Sederajat) yang bekerja sebagai buruh di pabrik dan Diploma/Sarjana yang bekerja di instansi pemerintah/swasta. Sehingga diperlukan adanya sosialisasi edukasi perilaku orang tua dalam pemberian MP-ASI pada balita di Dusun Kodokan, Desa Papahan, Kecamatan Tasikmadu, Kabupaten Karanganyar, Jawa Tengah. Adapun kegiatan tersebut dilakukan dalam bentuk penyuluhan dengan memberikan pretes dan postes kepada peserta dan hasil dari kegiatan sosialisasi tersebut diperoleh peningkatan nilai postes sebesar 34\%. Maka dapat dikatakan bahwa kegiatan penyuluhan memberikan dampak positif terhadap peningkatan pengetahuan peserta, sehingga kegiatan ini dapat dikatan berhasil sesuai indikator keberhasilan (peningkatan nilai postes $25 \%$ ).
\end{abstract}

Kata Kunci: MP-ASI, ASI Eksklusif, Penyuluhan

\section{Abstract}

The period of golden growth in infants and children can be realized if you get the appropriate nutritional intake. In order to achieve optimal growth and development, in the Global Strategy for Infant and Young Child Feeding, WHO / UNICEF recommends four essential things that must be done namely; first giving breast milk to the baby immediately within 30 minutes after the baby is born, second giving only breast milk (ASI) solely or exclusively breastfeeding from birth until the baby is six months old, third giving complementary food for breast milk (MP-ASI) ) from 6 months to 24 months of age, and fourth continue breastfeeding until the child is 24 months or older (WHO, 2000). Based on observations of data at the Kodokan Hamlet Posyandu that most of the mothers of children under five or close family members have given MP-ASI early (70\%) of the number of toddlers there are 55 toddlers and of 55 mothers of toddlers. Toddlers in the Kodokan Hamlet Posyandu consist of ages 0-6 months (7.3\%), ages 7-12 months (10.9\%), ages 1-3 years (47.3\%), ages 4-5 years (34.5\%). Most of the latest education for mothers of children under five in the Kodokan Hamlet is an average high school (SMA / equivalent) who works as a laborer in a factory and a Diploma / Bachelor who works in a government / private agency. So it is necessary to educate parents about behavioral education in giving MP-ASI to toddlers in Kodokan Hamlet, Papahan Village, Tasikmadu District, Karanganyar Regency, Central Java. The activity was carried out in the form of counseling by giving pretest and posttest to participants and, the results of the socialization activity obtained an increase in posttest value of $34 \%$. Then it can be said that extension activities have a positive impact on increasing the knowledge of participants so that these activities can be said to be successful according to indicators of success (increase in posttest scores by $25 \%)$.

Keywords: MP-ASI, ASI Ekslusif, Persuasion 


\section{PENDAHULUAN}

Usia 0-24 bulan merupakan masa pertumbuhan dan perkembangan yang pesat, sehingga kerap diistilahkan sebagai periode emas sekaligus periode kritis. Periode emas dapat diwujudkan apabila pada masa ini bayi dan anak memperoleh asupan gizi yang sesuai untuk tumbuh kembang optimal. Guna mencapai tumbuh kembang optimal, di dalam Global Strategy for Infant and Young Child Feeding, WHO/UNICEF merekomendasikan empat hal penting yang harus dilakukan yaitu; pertama memberikan air susu ibu kepada bayi segera dalam waktu 30 menit setelah bayi lahir, kedua memberikan hanya air susu ibu (ASI) saja atau pemberian ASI secara eksklusif sejak lahir sampai bayi berusia 6 bulan, ketiga memberikan makanan pendamping air susu ibu (MP-ASI) sejak bayi berusia 6 bulan sampai 24 bulan, dan keempat meneruskan pemberian ASI sampai anak berusia 24 bulan atau lebih (WHO, 2000).

Makanan pendamping ASI adalah makanan dan minuman yang mengandung gizi, diberikan pada bagi atau anak yang berumur $6-24$ bulan untuk memenuhi kebutuhan gizinya. Pentingnya pemberian MP-ASI secara tepat berpengaruh terhadap pertumbuhan dan perkembangan anak. Kerugian yang ditimbulkan oleh pemberian MP-ASI dini diantaranya mengalami gangguan menyusui, beban ginjal yang terlalu berat sehingga mengakibatkan hiperosmolaritas plasma, alergi terhadap makanan, dan gangguan pencernaan atau diare. WHO menyelenggarakan konvensi Expert Panel Meeting yang meninjau lebih dari 3000 makalah riset dan akhirnya diambil kesimpulan bahwa 6 bulan ( usia $0-6$ bulan ) merupakan periode yang optimal untuk pemberian ASI Eksklusif (Gibney, 2009). Menurut data Riskesdas (2018) bayi yang mendapatkan ASI Eklusif berdasarkan wilayah perkotaan sebesar $(40,7 \%)$ dan wilayah desa sebesar $33,6 \%$. Berdasarkan pendidikan terakhir, orang tua yang memberikan ASI eklusif terdapat pada kelompok tertinggi orang tua yang berpendidikan SLTA/sederajat $(41,9 \%)$ sedangkan yang terendah yaitu pada pendidikan orang tua yang tidak bersekolah (33,7\%). Adapun konsumsi makanan beragam pada bayi usia $6-23$ bulan tertinggi jatuh pada propinsi DIY $(69,1 \%)$ dan terandah pada propinsi Maluku Utara (16,79\%). Berdasarkan pendidikan orang tua, pemberian makanan beragam diberikan oleh orang tua yang berpendidikan tamat D1/D2/D3/S1 sederajat $(57,9 \%)$. Sedangkan berdasarkan wilayah perkotaan pemberian makanan yang beragam lebih banyak di daerah perkotaan (52,4\%) daripada di pedesaan (40,8\%) (Riskesdas, 2018).

Berdasarkan studi pendahulauan Penduduk Dusun Kodokan, Desa Papahan memiliki latar belakang pendidikan yang hampir $60 \%$ penduduknya berpendidikan SMA ke bawah dengan bermata pencaharian sebagai petani dan buruh pabrik. Banyak ibu-ibu muda yang menitipkan balitanya pada orang tua mereka, dan hampir $70 \%$ lebih para balita telah diberi MP-ASI dini oleh anggota keluargaterdekat atau nenek dari balita dikarenan kesibukan para orang tua yang bekerja. Data ini diperoleh dari hasil observasi dan wawancara dengan salah satu pengurus PKK di Dusun Kodokan, Desa Papahan. Permasalahan yang terjadi para ibu balita sibuk dengan aktifitas pekerjaannya di luar untuk mambantu kehidupan keluarga dan para balita dititipkan pada nenek dan atau saudara terdekatnya. Kesibukan dari para ibu tersebut memicu kecukupan asupan ASI pada bayi sangat terbatas sehingga nenek dan atau saudara terdekat tanpa sepengetahuan dari ibu balita telah memberikan MP-ASI Dini pada balita. Adapun MP-ASI Dini yang sering diberikan biasanya berupa madu, pisang, bubur instan, susu formula dan sejenisnya. Disamping itu, peran ibu dalam Praktek ASI Eksklusif masih sangat rendah. Hal ini dikarenakan kurangnya pengetahuan akan pentingnya ASI Eksklusif dan juga ketidaksabaran dalam manajemen pengelolaan ASI Eksklusif. Program perbaikan gizi yang bertujuan meningkatkan jumlah dan mutu MP-ASI, selama ini telah dilakukan, diantaranya pemberian MP-ASI kepada bayi dan anak usia 6-24 bulan pada keluarga miskin. Pemberian MP-ASI yang sudah dilakukan oleh petugas PKK berupa MP-ASI buatan pabrikan. (Data Primer, 2019).

Berdasarkan rekomendasi dari WHO menekankan, secara sosial budaya MP-ASI hendaknya dibuat dari bahan pangan yang murah dan mudah diperoleh di daerah setempat (indigenous food) (WHO, 2000). Pemberian MP-ASI lokal memiliki beberapa dampak positif, antara lain; ibu lebih memahami dan lebih terampil dalam membuat MP-ASI dari bahan pangan lokal sesuai dengan kebiasaan dan sosial budaya setempat, sehingga ibu dapat melanjutkan pemberian MP-ASI lokal 
secara mandiri; meningkatkan partisipasi dan pemberdayaan masyarakat serta memperkuat kelembagaan seperti PKK dan Posyandu; memiliki potensi meningkatkan pendapatan masyarakat melalui penjualan hasil pertanian; dan sebagai sarana dalam pendidikan atau penyuluhan gizi.

Berdasarkan permasalahan diatas maka perlu adanya pelaksanaan penyuluhan yang didasarkan pada studi telaah dan wawancara dari petugas Posyandu Dusun Kodokan bahwa sebagian besar ibu balita atau anggota keluarga dekat telah memberikan MP-ASI dini sebesar (70\%) dari jumlah balita yang ada yaitu 55 balita dan dari 55 orang ibu balita. Balita yang ada di Posyandu Dusun Kodokan ini terdiri dari usia $0-6$ bulan (7,3\%), usia $7-12$ bulan (10,9\%), usia 1-3 tahun (47,3\%), usia 4-5 tahun (34,5\%). Sebagian besar pendidikan terakhir ibu balita di Dusun Kodokan rata-rata Sekolah Menengah Atas (SMA/Sederajat) yang bekerja sebagai buruh di pabrik dan Diploma/Sarjana yang bekerja di instansi pemerintah/swasta. Sehingga penyuluhan yang kami lakukan yaitu tentang 'Edukasi Perilaku Orang Tua Dalam Pemberian MP-ASI Pada Balita di Posyandu Dusun Kodokan, Desa Papahan, Kecamatan Tasikmadu, Kabupaten Karanganyar, Solo, Jawa Tengah Tahun 2019".

\section{METODE}

Metode yang Kami gunakan adalah pemberian edukasi berupa penyuluhan Pentingnya pemberian MP-ASI kepada Balita dan praktek pembuatan MP-ASI dalam upaya meningkatkan kesehatan Balita di Dusun Kodokan. Adapun alur tahapan yang telah kami laksanakan sebagai berikut:

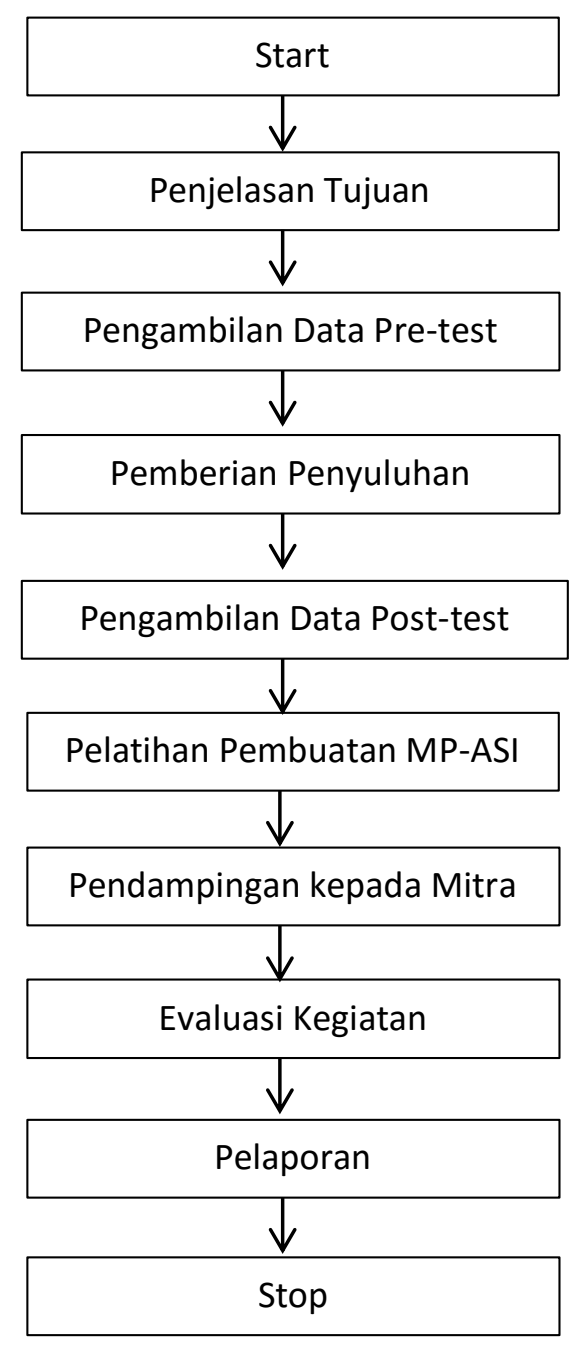

\section{Alur Kegiatan Teknis Penyuluhan MP-ASI Pada Ibu Balita}


Bagan 1. diatas adalah alur tahapan kegiatan teknis dalam penyuluhan MP-ASI pada ibu balita yang telah dilakukan. Jenis edukasi ini menggunakan metode pemberian penyuluhan dengan parameter hasil nilai pre-tes dan postes dan dilakukan evaluasi dengan memberikan penilaian dari jawaban soal teori. Standar Nilai Post Test minimal 70 (skala 100) setiap peserta. Indikator keberhasilan program adalah semua peserta yang mengikuti penyuluhan memiliki skor rata-rata pretes mengalami peningkatan dari skor postes sebesar $25 \%$.

\section{HASIL DAN PEMBAHASAN}

Kegiatan pengabdian masyarakat di Dusun Kodokan, Desa Papahan, Kecamatan Tasikmadi dilaksanakan pada bulan Agustus 2019 di ruang balai pertemuan PKK Dusun Kodokan. Kegiatan yang dilakukan meliputi penyuluhan kesehatan mengenai "Edukasi Perilaku Orang Tua dalam Pemberian MP-ASI Pada Balita di Posyandu Dusun Kodokan, Desa Papahan, Kecamatan Tasikmadu, Kabupaten Karanganyar, Solo, Jawa Tengah Tahun 2019". Sasaran kegiatan edukasi perilaku orang tua dalam pemberian MP-ASI pada balita ini diikuti oleh 40 orang tua (ibu muda dan atau orang tua yang mempunyai cucu, serta perwakilan remaja karangtaruna wanita) di Dusun Kodokan, Desa Papahan, Kecamatan Tasikmadu, Kabupaten Karanganyar, Jawa Tengah.

Kegiatan penyuluhan kesehatan ini dilakukan melalui beberapa tahapan sebagai berikut, yaitu ; Tahap pertama adalah Persiapan Kegiatan. Kegiatan pengabdian masyarakat ini dimulai dengan pembuatan proposal kegiatan pengabdia, kemudian dilanjutkan mengajukan permohonan perijinan kegiatan pengabdian masyarakat kepada Kepala Dusun dan Ketua PKK Dusun Kodokan. Selain itu, panitia juga mengurus administrasi terkait surat undangan, presensi peserta dan menyiapkan bahan materi yang akan disampaikan. Peralatan yang dibutuhkan dalam kegiatan ini diantaranya laptop, proyektor, Icd, pointer, kamera, threeport, dan sound system. Tempat yang dipakai untuk kegiatan tersebut berada di ruang balai pertemuan PKK Dusun Kodokan.

Tahap kedua adalah Kegiatan Penyuluhan Edukasi. Sebelum kegiatan edukasi ini dimulai, acara ini dibuka dengan sambutan dari Kepala Dusun Kodokan yang diwakili oleh ibu Kadus ibu Dewi Anggraini. Kemudian dilanjutkan dengan pembagian kuesioner soal Pretest yang dilakukan oleh Saudara Ratih dan Dian Mei (Mahasiswa FKM Univet) kepada para peserta target. Setelah kegiatan pre test dilanjutkan sesi materi.

Tahap ketiga adalah Penyampaian Materi. Pertama pemateri memperkenalkan diri terlebih dahulu kemudian mencoba menggali pengetahuan dasar tentang MP-ASI dan ASI Eksklusif.
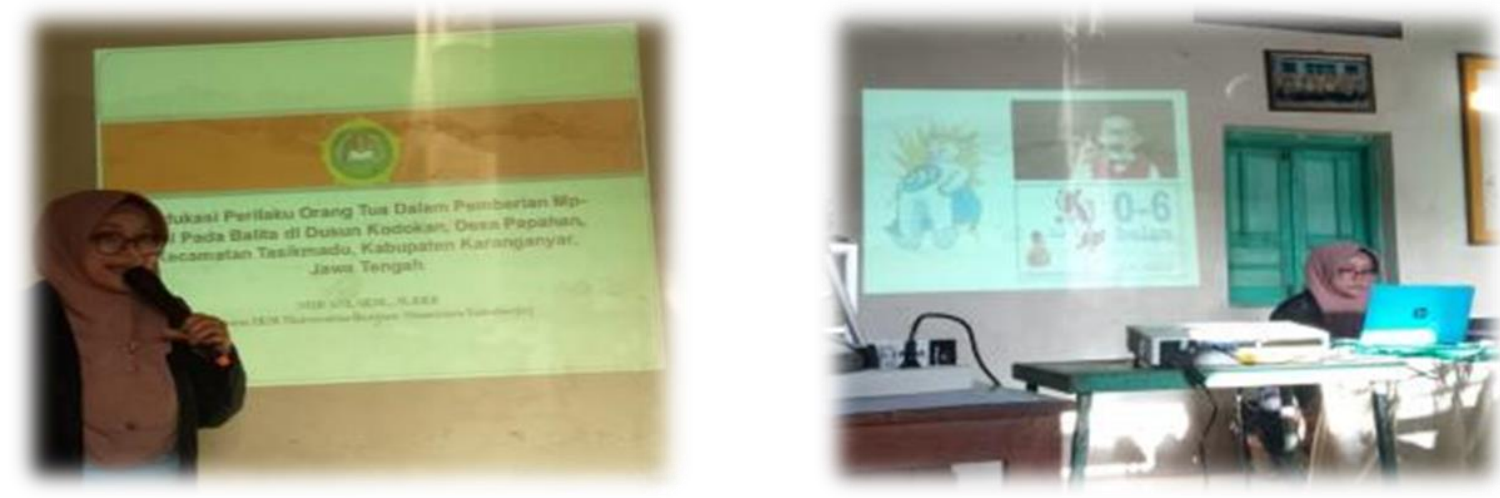

Foto Penyampaian Materi oleh Nur Ani, S.K.M., M.K.K.K.

Pemateri mengajukan beberapa pertanyaan mengenai pengertian MP-ASI dan/atau ASI Eksklusif yang baik dan benar. Setelah menggali pengetahuan dasar kemudian pemateri mulai memaparkan materi pendidikan kesehatan mengenai penjelasan ASI Eksklusif yang disampaikan oleh Farid Setyo Nugroho, S.K.M., M.Kes. sementara materi pentingnya pemberian MP-ASI bagi balita dan contoh menu MP-ASI beserta cara pembuatannya disampaikan oleh Nur Ani, S.K.M., M.K.K.K. Selama kegiatan penyuluhan 
ini di moderatori oleh ibu Wartini, S.K.M., M.Sc. Kegiatan ini berlangsung kurang lebih 3 jam dari jam 14.00-17.00 WIB hingga membuat peserta tampak antusias dan memperhatikan isi materi penyuluhan.

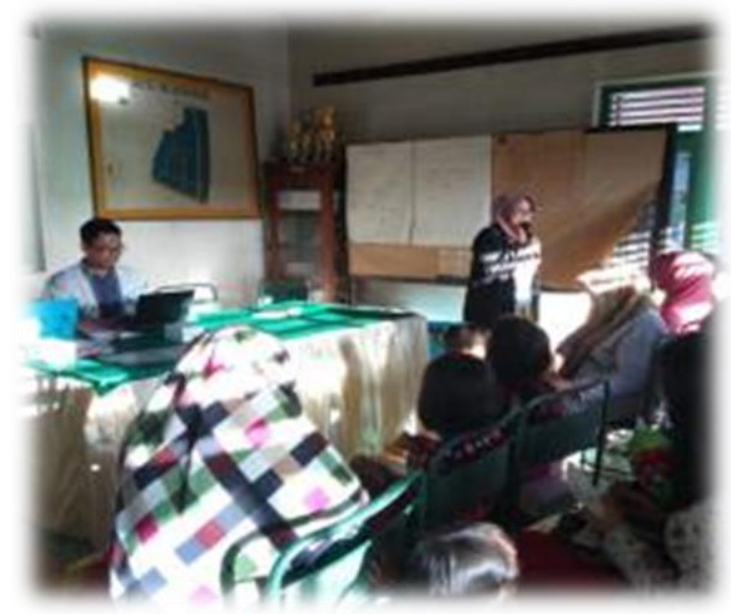

Foto Diskusi dan Tanya Jawab

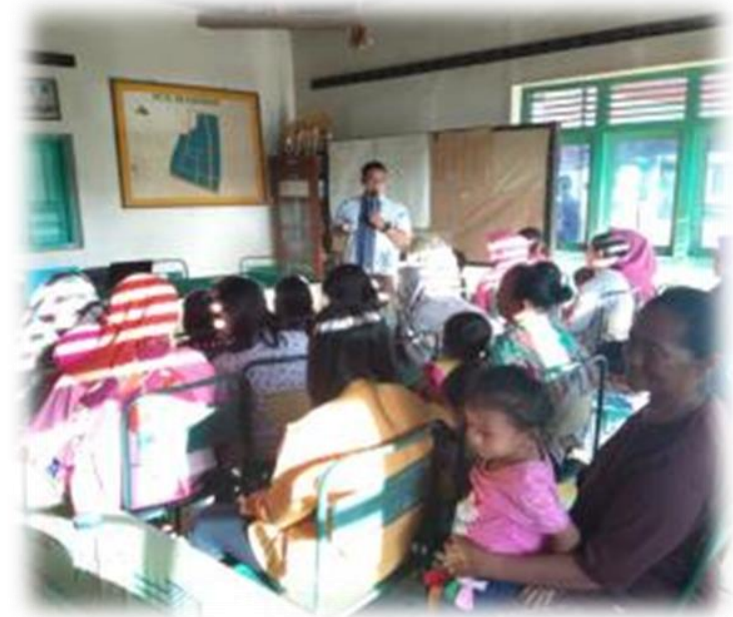

Foto Penyampaian Materi oleh Farid Setyo Nugroho, S.K.M., M.Kes.

Tahap keempat adalah sesi tanya jawab dan diskusi. Pada akhir sesi pemateri memberikan kesempatan kepada peserta untuk mengajukan pertanyaan terkait materi yang telah disampaikan. Didapatkan 3 pertanyaan dari peserta penyuluhan terkait isi materi. Tahap kelima adalah evaluasi dan penutup. Pada tahap ini pemateri melakukan evaluasi terkait pemberian materi yang telah disampaikan dengan cara memberikan pertanyaan postes kepada peserta untuk menjawab pertanyaan tersebut. Sebagai bentuk apresiasi terhadap kegiatan ini pihak panitia memberikan hadiah souvenir kepada seluruh peserta yang hadir dan ibu-ibu PKK yang telah membantu berlangsungnya kegiatan. Dilanjutkan ucapan terima kasih kepada Bp/Ibu Kepala Dusun Kodokan dan Ketua Ibu PKK Dusun Kodokan dan Foto bersama dengan peserta. Kegiatan ini berjalan lancar mulai dari awal pembukaan sampai akhir kegiatan.
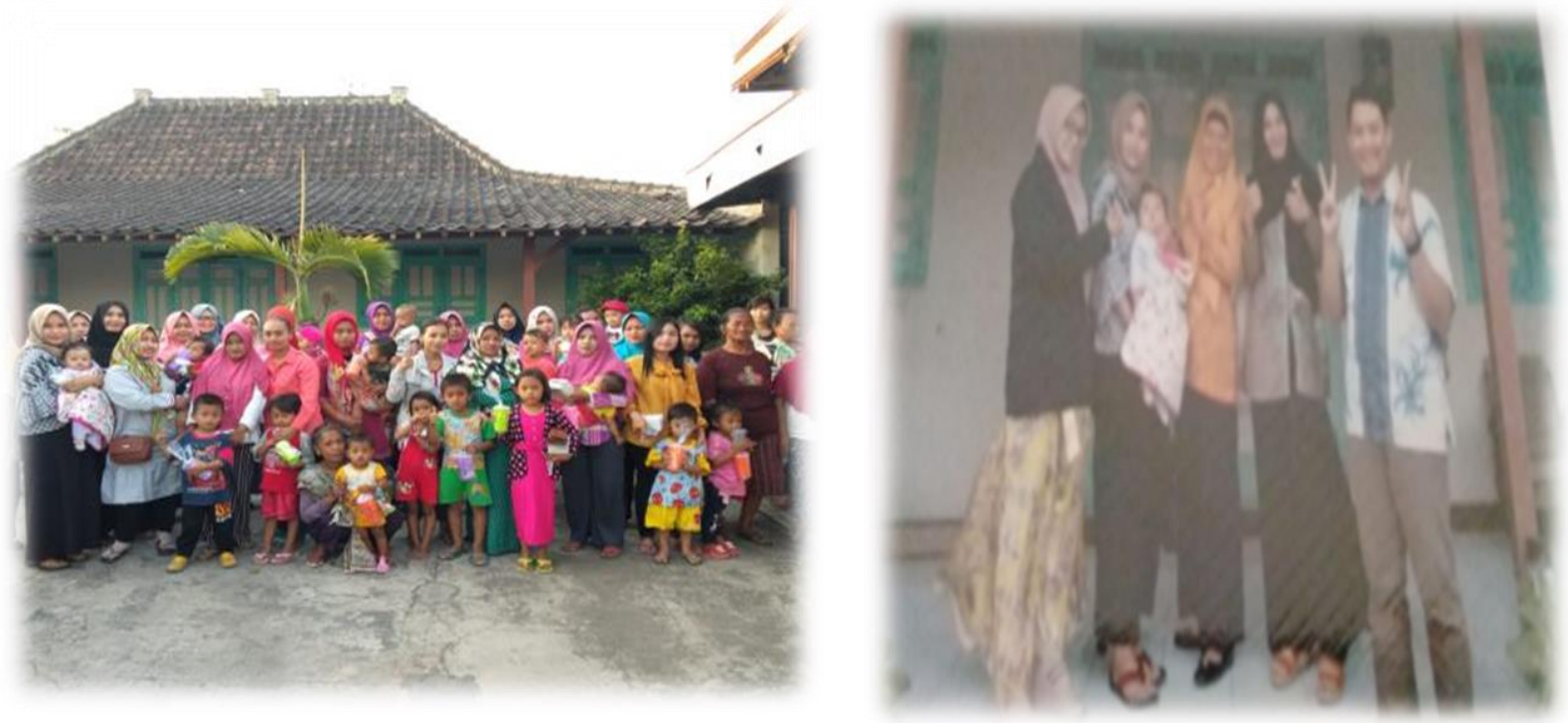

Foto Bersama Peserta dan Ibu Pengurus PKK Dusun Kodokan 
Adapun hasil yang diperoleh dari kegiatan pengabdian masyarakat ini adalah hasil nilai pretest dan post test mengalami peningkatan seperti yang tertuang dalam tabel berikut :

Tabel 1 Penilaian Pretest dan Post Test

Tingkat Pengetahuan tentang MP-ASI

\begin{tabular}{ccccc}
\hline & \multicolumn{2}{c}{ PRETEST } & \multicolumn{2}{c}{ POST TEST } \\
\cline { 2 - 5 } NILAI & (n) & $\%$ & (n) & $\%$ \\
\hline 50 & 8 & 20 & 0 & 0 \\
60 & 15 & 37,5 & 1 & 2,5 \\
70 & 10 & 25 & 0 & 0 \\
80 & 6 & 15 & 1 & 2,5 \\
90 & 1 & 2,5 & 3 & 7,5 \\
100 & 0 & 0 & 35 & 87,5 \\
\hline JUMLAH & $\mathbf{4 0}$ & & 40 & \\
RESPONDEN & & & & \\
\hline
\end{tabular}

Sumber : Data Primer (2019)

Diagram Penilain Pretest dan Post Test

Tingkat Pengetahum tentangMP-ASI

$\because$ PRETEST $=$ POSTTEST

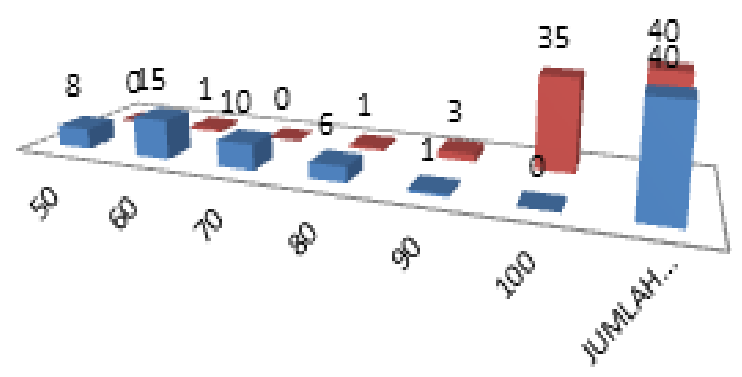

Sumber : Data Primer (2019)

Berdasarkan tabel 1 diatas menunjukkan bahwa nilai pretest tertinggi 90 sebanyak 1 orang, nilai terendah 50 sebanyak 8 orang, nilai modus 60 , nilai mean 64,25 . Sedangkan nilai post test tertinggi 100 sebanyak 35 orang, nilai terendah 60 sebanyak 1 orang, nilai modus 100, nilai mean 97,75. Sehingga dapat disimpulkan dari hasil penyuluhan diperoleh nilai rata-rata tingkat pengetahuan mengalami kenaikan sebesar $34 \%$.

Kegiatan edukasi perilaku orang tua dalam pemberian MP-ASI Pada Balita di Posyandu Dusun Kodokan, Desa Papahan, Kecamatan Tasikmadu, Kabupaten Karanganyar, Solo, Jawa Tengah Tahun 2019 terlaksana dengan baik bahkan para peserta terlihat antusias dan mengharapkan kegiatan penyuluhan dapat berlanjut dengan pemberian materi yang lainnya terutama terkait dengan pemberdayaan perempuan dan kesehatan. Pengurus PKK juga mengharapkan akan adanya kegiatan yang berkelanjutan sehingga semakin dapat meningkatkan pengetahuan ibu-ibu dan perempuan lainnya.

Berdasarkan evaluasi dan monitoring yang dilakukan maka rekomendasi yang kami ajukan bagi kegiatan ini adalah kegiatan serupa seharusnya dilaksanakan secara kontinyu yang menjadi program tahunan untuk meningkatkan pengetahuan dan kewaspadaan para ibu-ibu dan perempuan muda lainnya, terutama dibidang kesehatan khususnya tentang MP-ASI, ASI ekslusif, personal hygiene dan 
kegiatan pemberdayaan wanita yang bisa menunjang ekonomi. Kegiatan dapat berupa penyuluhan secara berkelanjutan kepada ibu-ibu dan remaja putri.

\section{SIMPULAN}

Kegiatan pengabdian kepada masyarakat mengenai Edukasi Perilaku Orang Tua Dalam Pemberian MP-ASI Pada Balita di Posyandu Dusun Kodokan, Papahan, Tasikmadu, Karanganyar, Jawa Tengah Tahun 2019 telah terlaksana dengan baik. Hasil kegiatan pengabdian kepada masyarakat pretest dan post test diperoleh peningkatan nilai pengetahuan sebesar $34 \%$. Didapatkan 3 pertanyaan dari peserta penyuluhan terkait materi penyuluhan dan peserta target mengharapkan ada kegiatan penyuluhan kembali terkait kesehatan dan pemberdayaan perempuan. Kegiatan pengabdian serupa dapat dilakukan secara rutin baik di lokasi yang sama maupun di lokasi yang berbeda dengan sasaran masyarakat yang benar-benar membutuhkan pelayanan kesehatan terutama mengenai kesehatan dan pemberdayaan masyarakat.

\section{UCAPAN TERIMA KASIH}

Penulis mengucapkan terima kasih kepada pihak yang telah memberi dukungan dana pelaksanaan pengabdian ini yaitu LPPM Universitas Veteran Bangun Nusantara. Tak lupa pula penulis mengucapkan terimakasih kepada Dekan dan Kaprodi Kesmas FKM Universitas Veteran Bangun Nusantara yang telah memberi support baik material maupun moril.

\section{DAFTAR REFERENSI}

Kartono, Djoko. dkk. (2014). Angka Kecukupan Gizi 2012 untuk Orang Indonesia (Prosiding Widyakarya Nasional Pangan dan Gizi X). LIPI Publisher: Jakarta.

Kemenkes RI. (2018). Hasl Utama Riskesdas. Kemenkes RI BPPK : Jakarta.

Nasar, Sri Sudaryati. (2015). Makanan Pendamping Asi (Mp-ASI): Pedoman dan Prinsip Pemberiannya.

https://sipeg.ui.ac.id/ng/arsipsk/20190822-Cat-1886a26ea293c5f4fa3b9e1bbab34c80.pdf

.Diakses 01 Agustus 2020.

Notoadmodjo S.(2012). Promosi Kesehatan dan Perilaku. Rineka Cipta : Jakarta. .(2010). Ilmu Perilaku Kesehatan. Rineka Cipta : Jakarta.

. (2007). Promosi Kesehatan dan Ilmu Perilaku. Rineka Cipta : Jakarta.

Setiawan S. 2009. Pemberian MP-ASI Dini dan Hubungannya dengan Kejadian Infeksi pada Bayi 0-6 buan di Wilayah Kerja Puskesmas Cipayung, Kota depok Tahun 2009. FKM UI : Jakarta.

Sugiyono. (2015). Teknologi Pangan dalam Pembuatan MP-ASI. https://sipeg.ui.ac.id/ng/arsipsk/20190822-Cat-1886a26ea293c5f4fa3b9e1bbab34c80.pdf .Diakses 01 Agustus 2020.

WHO.(2000). Complementary Feeding Family Foods for Breastfed Children (WH0/NHD100.1 WHO/FCWCAH/OO.6). Departement of Nutrition for Health and Development World Health Organization.

Wiguna, Tjhin. (2015). Faktor Psikososial Dan Intervensi Perilaku Terkait Proses Pemberian Makan Pada Anak Usia Bawah Tiga Tahun (Anak Usia Batita). https://sipeg.ui.ac.id/ng/arsipsk/20190822-Cat-1886a26ea293c5f4fa3b9e1bbab34c80.pdf .Diakses 01 Agustus 2020.

Williams L \& Wilkins. 2006. Modern Nutrition in Health and Disease $\left(10^{\text {th }}\right.$ ed.) A. Wolters Kluwer Company : United States of America.

Yuliarti, Klara . (2015). Recent Evidence of Breastfeeding: Long Term Benefits And Common Problems In Clinical Practice.

https://sipeg.ui.ac.id/ng/arsipsk/20190822-Cat-1886a26ea293c5f4fa3b9e1bbab34c80.pdf .Diakses 01 Agustus 2020. 